\title{
Analysis of Agricultural Land Use Change in the Middle Reach of the Heihe River Basin, Northwest China
}

\author{
Li Fu ${ }^{1,2}$, Lanhui Zhang ${ }^{3}$ and Chansheng $\mathrm{He}^{2,3, *}$
}

1 Key Laboratory of Digital Earth Science, Institute of Remote Sensing and Digital Earth, Chinese Academy of Sciences, Beijing 100101, China; E-Mail: fuli@irsa.ac.cn

3 Center for Dryland Water Resources Research and Watershed Sciences, Key Laboratory of Western China's Environmental Systems (MOE), Lanzhou University, Lanzhou 730000, China; E-Mail: zhanglanh06@1zu.cn

* Author to whom correspondence should be addressed; E-Mail: he@wmich.edu; Tel.: +1-269-387-3425; Fax: +1-269-387-3442.

Received: 5 November 2013; in revised form: 13 February 2014 / Accepted: 19 February 2014 / Published: 4 March 2014

\begin{abstract}
The Heihe River Basin (HRB) is the second largest inland river basin in arid Northwest China. The expanding agricultural irrigation, growing industrialization, and increasing urban development in the middle reach have depleted much of the river flow to the lower reach, degrading the corresponding ecosystems. Since the enactment of the State Council of China's new HRB water allocation policy in 2000 tremendous land use and land cover (LULC) changes have taken place to reduce water consumption in the middle reach and deliver more water downstream. This paper analyzes LULC changes during the period of 2000-2009 to understand how the changing land use patterns have altered water resource dynamics in the region. Results, while yet to be further verified in the field, show that from 2000 to 2009, urban, agricultural land, rangeland, and forest areas have increased, and barren area has decreased. Within the cropland, rice (a high water consumption crop) planting area decreased, while corn and wheat (relatively lower water consumption crops) planting areas increased. These changes in land use patterns, especially in the agricultural zones, have ensured the discharge of the required amount of water to the lower reach.
\end{abstract}


Keywords: Heihe River Basin; land use and land cover change (LULCC); agriculture; discharge

\section{Introduction}

Land use and land cover (LULC) changes, such as the conversion of land use types like grasslands, woodlands and forests into croplands and pastures are responsible for contributing $20 \%-75 \%$ of all atmospheric emissions of greenhouse gases [1], and for causing deteriorating ecological diversity, soil fertility, water and air quality [2-4]. Different approaches and datasets have been used to detect and understand LULC changes and the related driving forces. For example, Serra and colleagues [5] analyzed LULC changes in the Mediterranean region by using a hybrid classifier of remote sensing data and explored the main driving forces of the LULC using a multiple logistic regression method. The authors stated that the environmental protection polices and expansion of tourism led to the LULC change, and the increase of irrigated herbaceous crops within the region would lead to greater agricultural water demands and intensify conflicts among different water uses [5]. LULC detection is also important for crop irrigation and water resources management at the watershed scale [6]. A study in the Indus Basin using multi-temporal remote sensing-based products captured seasonal phenological information of different crops for crop classification, and subsequently used such information to identify different water users and to formulate water management plans [7]. Schilling et al. [8] analyzed the impacts of shifting crop pattern from mixed perennial/annual cropping system to an annual system of corn and soybean row crops over the last century in the corn belt region of the United States, and reported that the changing crop patterns have altered the water balance of the Raccoon River watershed, decreasing evapotranspiration (ET) and increasing streamflow and base flow. In a similar study, Schilling et al. [9] using statistical analysis of annual discharge and precipitation in the Mississippi River, indicate that expanding soybean acreage in the basin is the main factor that caused the increasing discharge of the Upper Mississippi River Basin. Moreover, LULC change affects not only the quantity of water but also the quality of water [10,11].

LULC changes in China, as elsewhere, are being driven by multiple demands for food production, industrial development, and urban expansion for the growing population [12]. Supported by a dynamic LULC information system, Liu and his colleagues [13,14] implemented China's land use change detection program during the mid-1990s to 2000. The results revealed that a great portion of the arable land in China's traditional agricultural zones had been occupied by built-up and residential areas, while changes in production conditions, economic benefits and climate conditions had led to the reclamation of arable land in northern China [13,14]. They also reported the initial success of the "returning arable land into woodland or grassland" policies [14]. Another study by Weng [15] investigated the land use change dynamics in the Zhujiang Delta by the combined use of remote sensing and geographic information system (GIS), and reported notably uneven urban growth and tremendous cropland losses in this fast growing coastal region. A similar research in this region conducted by Li [16] compared the differences between the western and eastern development corridors in the Zhujiang region, identified the spatial dependency of land use changes, and highlighted the 
influence of enforcing land use polices on the direction and magnitude of landscape changes. Another study by Xiao et al. [17] in Shijiazhuang City revealed that governmental policies were among the major drivers that influenced the LULC change in the city [17]. Many studies such as those discussed above have focused on the LULC change patterns in the fast growing metropolitan areas in eastern China, relatively few studies have addressed LULC change patterns in agricultural watersheds in arid Northwest China, particularly their impacts on water resources [12,18]. This research, through a case study of the Heihe River Basin (HRB), analyzes the pattern and rates of LULC changes in the middle reach and evaluates the impacts of these changes on streamflow discharges downstream for ecosystem protection.

The HRB (Figure 1) is the second largest inland river basin in arid Northwest China. The middle reach of the HRB has an agricultural history going back over 2,000 years owning to the flat land, adequate sunlight, and convenient water sources coming from the Qilian Mountains [19].

Figure 1. The boundary of the Heihe River Basin in Northwest China.

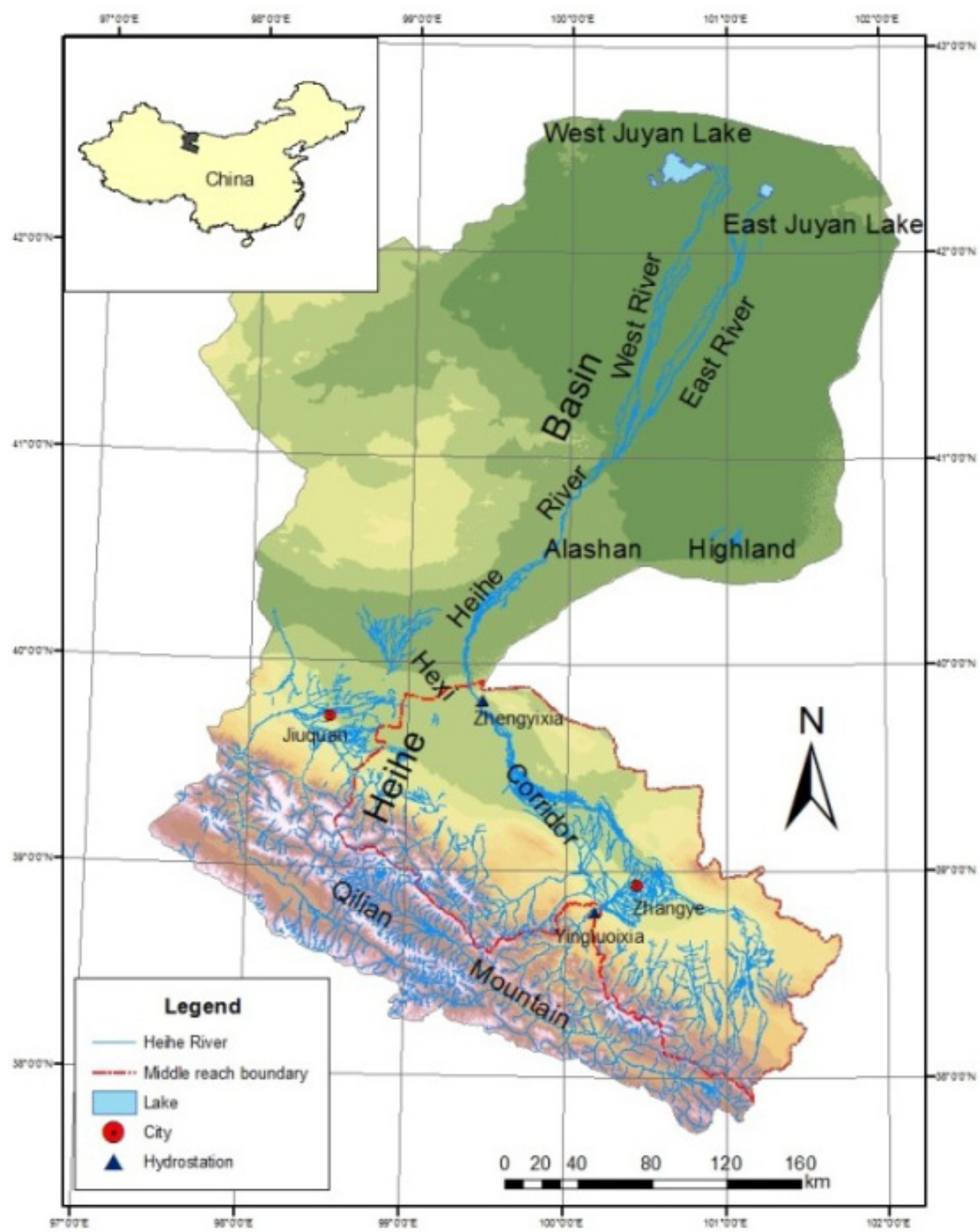


Human activities like reclaiming fallow land, constructing water supply projects and developing irrigated agriculture, have changed the natural landscape significantly $[18,19]$. Over the past few decades, the increased withdrawals for agricultural irrigation and municipal water supplies in the Hexi Corridor of the HRB since the 1970s have depleted much of the river flows to the lower reach, shrinking the East Juyan Lake and drying up the West Juyan Lake, endangering aquatic ecosystems and accelerating desertification [20]. To mitigate the damages to the ecosystem and improve the living conditions in the lower reach, the State Council of China issued an executive order in 2000, mandating that Gansu Province distribute about $0.95 \times 10^{9} \mathrm{~m}^{3}$ water per year under the normal climate years to the lower reach users. To implement the mandate, since 2000 local governments in the middle reach (particularly, Zhangye City) have made adjustments to the dominant crops and cropping patterns, most notably reducing or eliminating rice planting and increasing corn planting to save more water for downstream users [20]. Few studies have evaluated the LULC changes and their feedbacks to the water resources allocation in the HRB region. Thus, this study was undertaken to: (1) identify the LULC change patterns in the middle reach of the HRB between 2000 and 2009, especially in the cropland zones; and (2) assess the influences of LULC changes on water resource distributions in the study area.

\section{Methods}

\subsection{Study Area}

The HRB, the second largest inland river basin in arid Northwest China, is located between $96^{\circ} 42^{\prime} \sim 102^{\circ} 00^{\prime} \mathrm{E}$ and $37^{\circ} 41^{\prime} \sim 42^{\circ} 42^{\prime} \mathrm{N}$ and covers an area of approximately $128,000 \mathrm{~km}^{2}$ (Figure 1). Sandwiched between the southern Qilian Mountains and the northern Alashan Highlands, the middle reach of the HRB is like a corridor trending from northwest to southeast, with elevation ranges between 1,300 and 2,500 $\mathrm{m}[19,20]$. The climate is characterized as arid, with mean annual precipitation varying from about $331 \mathrm{~mm}$ in the southern mountainous areas to less than $100 \mathrm{~mm}$ in the northern high-plain areas [19]. The inter-annual variability of the precipitation is as high as $80 \%$, and over $60 \%$ of the precipitation falling between June and August [19]. The mean annual air temperature is $8{ }^{\circ} \mathrm{C}$ in the lower part (northern) of the basin and decreases to $2.1^{\circ} \mathrm{C}$ in the south [19]. The most common vegetation in the area includes temperate dwarf shrub and subshrub desert vegetation dominated by Chenopodiaceae, Zygophyllaceae, Ephedranceae, Asteraceae, Poaceae, and Leguminosae species [19].

The Hexi Corridor, located in the middle reach of $\mathrm{HRB}$, is an important source of commodity grain in China, supporting more than 97\% of the HRB's 1.8 million inhibits in two metropolitan areas: Zhangye (population 1.25 million in 2000) and Jiuquan (population 0.49 million in 2000) [20]. As the largest oasis in the middle reach, the Hexi Corridor is the major water consumer in the HRB, where $86 \%$ of the water withdrawal from the Heihe River was used to irrigate the farmland in the Corridor [20]. The main crops are spring wheat, corn and rice. Spring wheat is generally sown in late March and harvested during the middle of July, corn and rice are planted in April and harvested during September [20]. 


\subsection{Data Sources}

Two sets of $30 \mathrm{~m}$ resolution Landsat 5 and 7 images, acquired in 2000 and 2009, respectively, were downloaded from the United States Geological Survey (USGS) website (http://earthexplorer.usgs.gov/) [21] for mapping the 2000 and 2009 LULC types in the middle reach of the HRB (Table 1). The collected satellite images were taken in the growing season of the plants for better distinguishing vegetation from other land cover types. Additionally, ancillary data of 2000 LULC map of the HRB and 2008 air photo of Zhangye City were also collected to assist the classification of the LULC types. Agricultural statistics data, streamflow data from the Zhengyixia gauge station (outlet of the middle reach) and Yingluoxia gauge station (outlet of the upper reach), the 2000-2009 precipitation data of Qilian weather station were also acquired to analyze the influences of the LULC changes on water allocation in the study area. All of these data were obtained from the Cold and Arid Regions Environmental and Engineering Research Institute, Chinese Academy of Sciences.

Table 1. Satellite images used in this study.

\begin{tabular}{cccccc}
\hline Date & Path-Row & Satellite & Sensor & Cloud Cover & Preprocessing \\
\hline 10 August 2000 & $133-33$ & Landsat-7 & ETM+ & $<10 \%$ & Geometric Correction \\
10 August 2000 & $133-34$ & Landsat-7 & ETM+ & $<10 \%$ & Geometric Correction \\
14 June 2000 & $134-32$ & Landsat-7 & ETM+ & $<10 \%$ & Geometric Correction \\
14 June 2000 & $134-33$ & Landsat-7 & ETM+ & $<10 \%$ & Geometric Correction \\
8 November 2009 & $133-33$ & Landsat-5 & TM & $<10 \%$ & Geometric Correction \\
8 November 2009 & $133-34$ & Landsat-5 & TM & $<10 \%$ & Geometric Correction \\
17 July 2009 & $134-32$ & Landsat-5 & TM & $<10 \%$ & Geometric Correction \\
17 July 2009 & $134-33$ & Landsat-5 & TM & $<10 \%$ & Geometric Correction \\
\hline
\end{tabular}

\subsection{Image Processing}

The collected images have already been geo-referenced to WGS84 UTM Zone 47N. These images were then radiometrically corrected using the calibration utility for Landsat in ENVI $4.7^{\mathrm{TM}}$ software package. Atmospheric correction was also conducted in ENVI, using the automatic calculated dark object method, to reduce the influence of atmospheric effects from the different images. The pre-processed images were subsequently clipped to the boundary of the study area.

Supervised classification method was used to map the 2000 and 2009 land cover types. The Chinese Land Resource Classification System, from the Cold and Arid Regions Environmental and Engineering Research Institute of Chinese Academy of Sciences, was used as the classification scheme to categorize the pixels of the two images. The classification system includes 6 major types (Level 1), i.e., cropland, forestland, grassland, water, urban and/or built-up land, and barren land. These types were then further discriminated into more detailed land cover types based on the differences in land characteristics, coverage and uses (Level 2, Table 2). Because the paved surfaces of urban area and barren land/or desert in the study area both have similar reflectance values, it is very difficult to differentiate them. Thus, to increase the accuracy of classification, the boundary of the urban areas extracted from the 2000 LULC map was used to mask out the pixels of the urban areas within the 2000 and 2009 Landsat images. A modified version of the Chinese Land Resource 
Classification System was used for classification, including six classes (agricultural land, forest, rangeland, water, barren land and perennial snow or ice). Within this classification system, water and perennial snow or ice is separated into two classes to show the glacial extent of the study area. Over 600 sites covering the six major land cover types were selected as the training sites in the study area. The 2000 LULC map and the shape files of roads and river flow network were used to help identifying the training sites. In addition, a normalized differential vegetation index (NDVI) image calculated in ENVI was also produced to better differentiate between vegetated and barren land areas. Then, the 2000 and 2009 images within the study area were classified using ENVI employing a maximum likelihood classification. Each pixel was assigned to a class that has the highest probability.

Table 2. The Chinese Land Resource Classification System.

\begin{tabular}{|c|c|c|c|}
\hline \multicolumn{2}{|c|}{ Level 1} & \multicolumn{2}{|c|}{ Level 2} \\
\hline \multirow{2}{*}{1} & \multirow{2}{*}{ Cropland } & 11 & Paddy \\
\hline & & 12 & Dry farmland \\
\hline \multirow{2}{*}{2} & \multirow{2}{*}{ Forestland } & 21 & Forest land \\
\hline & & 22 & Brush land \\
\hline \multirow{3}{*}{3} & \multirow{3}{*}{ Grassland } & 31 & High degree overlay grassland \\
\hline & & 32 & Middle degree overlay grassland \\
\hline & & 33 & Low degree overlay grassland \\
\hline \multirow{4}{*}{4} & \multirow{4}{*}{ Water } & 41 & River and channel \\
\hline & & & Lake \\
\hline & & 43 & Reservoir \\
\hline & & 44 & Ice and snow \\
\hline 5 & Urban and/or Built-up land & 51 & City and town \\
\hline \multirow{5}{*}{6} & \multirow{5}{*}{ Barren land } & 61 & Sand land \\
\hline & & 62 & Gobi \\
\hline & & 63 & Saline-alkali-land \\
\hline & & 65 & Barren land \\
\hline & & 66 & Rock and gravel land \\
\hline
\end{tabular}

To evaluate the changes within the agricultural land, but avoid the influence of the wetlands in the middle reach of the study area, we chose one scene satellite image (path 133, row 33) from both 2000 and 2009 data with little or no wetland distribution. We then masked out the agricultural land using the classification results, and then further classified it into three groups: corn, wheat and rice areas, also using a maximum likelihood classifier as described above. The selected image (path 133, row 33) was also ideal for distinguishing these three crops in the area, as among the multiple dates of the images acquired only this scene from August met the requirement for crop chronology analysis. In the study area, spring wheat is normally harvested by July, and corn is harvested in September. Use of August satellite images for classification is relatively more effective for differentiating the wheat from the corn planting area in the study region.

Accuracy assessment was conducted to evaluate the classification results. Sample points were selected using a stratified random method. The sample size was selected from a sample of $10 \%$ of the pixels proportional to the total number of pixels in each of the sample classes. The LULC map of 2000 from the Chinese Academy of Sciences was used as a ground truth reference for assessing the accuracy 
of the image classification for 2000. For the 2009 image classification maps of both the study area and the agricultural land area within the subset area, the 2008 air photo from the Chinese Academy of Sciences was used as a reference as this is the only high resolution data available. Contingency tables were derived to indicate the producer's accuracy, the user's accuracy, overall accuracy, and the Kappa coefficient. Each row of the table represents the truth in a predicted class, while each column represents the results of image-derived classification.

\section{Results}

\subsection{Classified LULC in the Middle Reach of the HRB}

Figure 2 shows both 2000 and 2009 LULC classification maps. The contingency tables (confusion matrices) (Tables 3 and 4) indicate the degree of misclassification among all the classes derived from the images. Each confusion matrix contains the overall accuracy percentage and the Kappa coefficient, and the classification accuracy is assessed through evaluating the overall classification accuracy and Kappa Statistics [22].

Figure 2. The LULC maps of the middle reach of the HRB for 2000 (left) and 2009 (right).
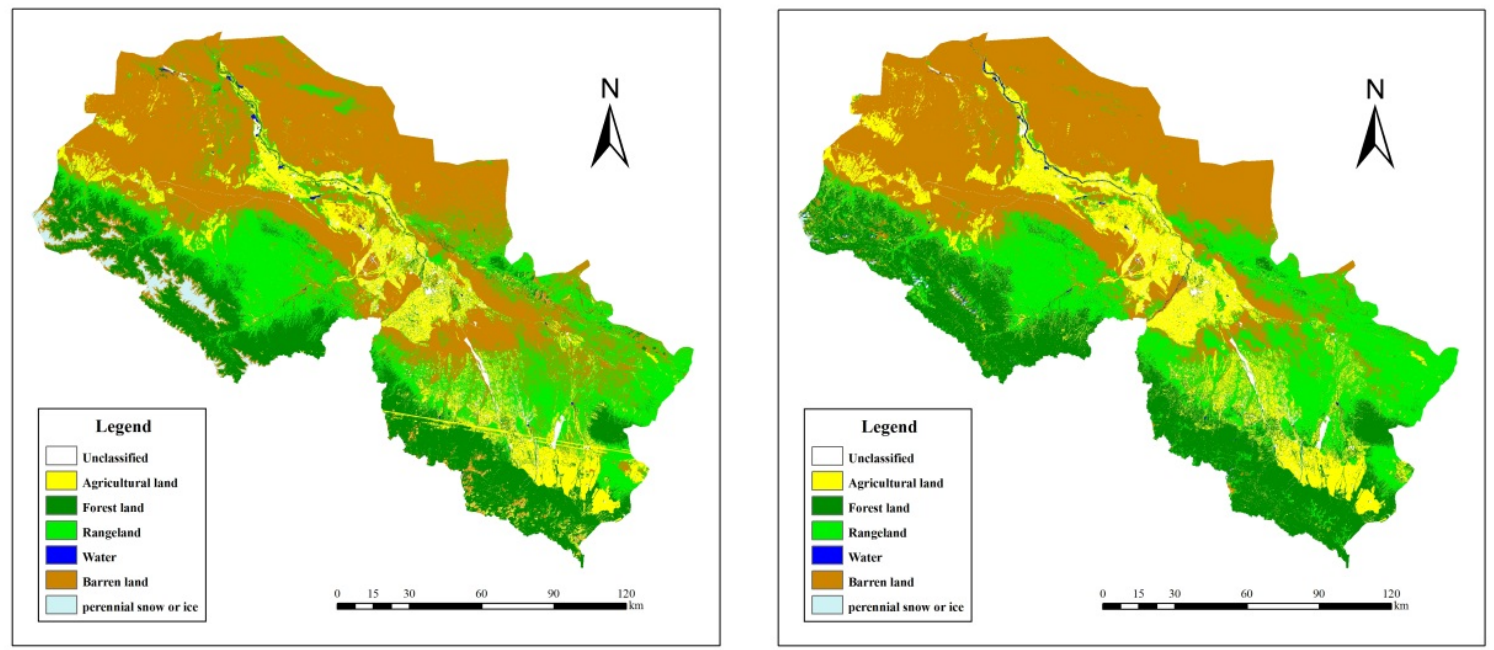

The overall classification accuracies are $86.53 \%$ and $85.80 \%$ in 2000 and 2009 , respectively (Tables 3 and 4). The Kappa statistics are 0.77 for both the 2000 and 2009 results. In 2000 and 2009 LULC classification confusion matrices, the accuracy rates of rangeland are relatively low, meaning actual rangelands were misclassified to other types, such as agricultural and barren land due to the similar spectral reflectance values of the rangeland, agricultural region and barren land within the particular region.

According to the 2000 LULC map, $43.25 \%$ of the middle reach of the HRB (total $27,955 \mathrm{~km}^{2}$ ) was dominated by barren land $\left(12,089.43 \mathrm{~km}^{2}\right) .22 .23 \%$ of the land was forest $\left(6,213.26 \mathrm{~km}^{2}\right)$ and $18.39 \%$ was rangeland $\left(5,142.19 \mathrm{~km}^{2}\right)$. Agricultural land $\left(3,685.30 \mathrm{~km}^{2}\right)$ constituted $13.18 \%$ of the study area. The remaining $1.67 \%$ of the middle reach of the HRB $\left(467.95 \mathrm{~km}^{2}\right)$ was covered by water, ice and snow (Table 5). 
Table 3. Contingency table of derived 2000 LULC map.

\begin{tabular}{lcccccccc}
\hline $\begin{array}{c}\text { Land Cover } \\
\text { Type }\end{array}$ & Agriculture & Forest & Rangeland & Water & Barren & $\begin{array}{c}\text { Ice and } \\
\text { Snow }\end{array}$ & Total & $\begin{array}{c}\text { User's } \\
\text { Accuracy }\end{array}$ \\
\hline Agriculture & $\mathbf{8 0 . 2 5}$ & 3.66 & 1.87 & 0 & 0.39 & 0 & 5.16 & 78.34 \\
Forest & 2.45 & $\mathbf{8 9 . 6 8}$ & 21.03 & 2.25 & 0.05 & 0 & 17.31 & 77.04 \\
Rangeland & 8.93 & 1.43 & $\mathbf{7 1 . 8 9}$ & 0 & 9.19 & 0 & 19.26 & 67.75 \\
Water & 0 & 0.02 & 0 & $\mathbf{9 7 . 7 1}$ & 0 & 0 & 0.08 & 95.96 \\
Barren & 8.37 & 4.08 & 5.21 & 0.04 & $\mathbf{9 0 . 3 4}$ & 0.09 & 56.54 & 96.51 \\
Ice and Snow & 0 & 1.10 & 0 & 0 & 0 & $\mathbf{9 9 . 9 1}$ & 1.63 & 89.99 \\
Total & 100 & 100 & 100 & 100 & 100 & 100 & $\mathbf{1 0 0}$ & \\
Producer's & 80.25 & 89.68 & 71.89 & 97.71 & 90.34 & 99.91 & & \\
Accuracy & & & & & & & & \\
\hline Overall Accuracy $=\mathbf{8 6 . 5 3 \%}$ Kappa Coefficient $=0.77$. & &
\end{tabular}

Table 4. Contingency table of derived 2009 LULC map.

\begin{tabular}{lcccccccc}
\hline $\begin{array}{l}\text { Land Cover } \\
\text { Type }\end{array}$ & Agriculture & Forest & Rangeland & Water & Barren & $\begin{array}{c}\text { Ice and } \\
\text { Snow }\end{array}$ & Total & $\begin{array}{c}\text { User's } \\
\text { Accuracy }\end{array}$ \\
\hline Agriculture & $\mathbf{7 7 . 2 5}$ & 2.62 & 2.25 & 0.06 & 0.42 & 0 & 5.54 & 79.72 \\
Forest & 6.32 & $\mathbf{9 4 . 6 2}$ & 11.64 & 0.31 & 0.11 & 0 & 20.80 & 88.86 \\
Rangeland & 15.43 & 2.52 & $\mathbf{8 0 . 2 0}$ & 0 & 14.23 & 0 & 22.72 & 57.40 \\
Water & 0 & 0.01 & 0 & $\mathbf{9 9 . 4 6}$ & 0 & 0.04 & 0.06 & 96.61 \\
Barren & 1 & 0.18 & 5.91 & 0.17 & $\mathbf{8 5 . 2 1}$ & 0.00 & 50.78 & 97.92 \\
Ice and Snow & 0 & 0 & 0 & 0 & 0 & $\mathbf{9 9 . 9 6}$ & 0.07 & 99.75 \\
Total & 100 & 100 & 100 & 100 & 100 & 100 & $\mathbf{1 0 0}$ & \\
Producer's & 77.25 & 94.62 & 80.20 & 99.46 & 85.21 & 99.96 & & \\
Accuracy & & & & & & & & \\
\hline Overall Accuracy $=\mathbf{8 5 . 8 0 \%}$; Kappa Coefficient $=0.77$. & &
\end{tabular}

Table 5. 2000 and 2009 classified LULC types, area, percentage, and changes.

\begin{tabular}{lccccc}
\hline \multirow{2}{*}{$\begin{array}{l}\text { Land Cover } \\
\text { Type }\end{array}$} & \multicolumn{2}{c}{$\mathbf{2 0 0 0}$} & \multicolumn{2}{c}{$\mathbf{2 0 0 9}$} & Changes \\
\cline { 2 - 6 } & Area $\left.\mathbf{( k m}^{\mathbf{2}}\right)$ & Percentage (\%) & Area $\left.\mathbf{( k m}^{\mathbf{2}}\right)$ & Percentage (\%) & of Area \\
\hline Agriculture & $3,685.30$ & 13.18 & $4,431.12$ & 15.85 & 745.82 \\
Forest & $6,213.26$ & 22.23 & $6,850.19$ & 24.50 & 636.93 \\
Rangeland & $5,142.19$ & 18.39 & $5,993.69$ & 21.44 & 851.5 \\
Water & 31.78 & 0.11 & 77.63 & 0.28 & 45.85 \\
Barren & $12,089.43$ & 43.25 & $10,195.99$ & 36.47 & $-1,893.44$ \\
Ice and Snow & 436.17 & 1.56 & 50.42 & 0.18 & -385.75 \\
\hline
\end{tabular}

Similarly, in 2009, barren land in the area decreased to $10,195.99 \mathrm{~km}^{2}$, but was still the major land use type in the study area. The areas of forest $\left(6,850.19 \mathrm{~km}^{2}\right)$, rangeland $\left(5,993.69 \mathrm{~km}^{2}\right)$ and agricultural land $\left(4,431.12 \mathrm{~km}^{2}\right)$ have minor increases, which constituted $24.50 \%, 21.44 \%$ and $15.85 \%$ of the middle reach of the HRB, respectively. About $0.46 \%$ of the study area $\left(128.05 \mathrm{~km}^{2}\right)$ was covered by water, ice and snow (Table 5). 


\subsection{Agricultural Types in the Selected Subset of the Study Area}

Similar classification procedures were conducted in the selected subset area, using the selected images (Path 133, Row 33) in August 2000 and August 2009, respectively. The agricultural land was further classified into rice, wheat and corn, as shown in Figure 3. The overall accuracies of the classification are $88.60 \%$ and $89.92 \%$ in 2000 and 2009, respectively. The Kappa coefficient is 0.76 and 0.79 , respectively (Tables 6 and 7 ).

The areas of each crop types are calculated to identify the changes of each type. In 2000 the areas of wheat, corn and rice within the selected subset are $1,606.33 \mathrm{~km}^{2}, 1,352.29 \mathrm{~km}^{2}$ and $296.81 \mathrm{~km}^{2}$, respectively. While in 2009 , the area of wheat plant was $1,720.11 \mathrm{~km}^{2}$, corn area was $1,735.53 \mathrm{~km}^{2}$, and rice area was $150.64 \mathrm{~km}^{2}$.

Figure 3. The agricultural types within the selected subset in August, 2000 (left) and 2009 (right).
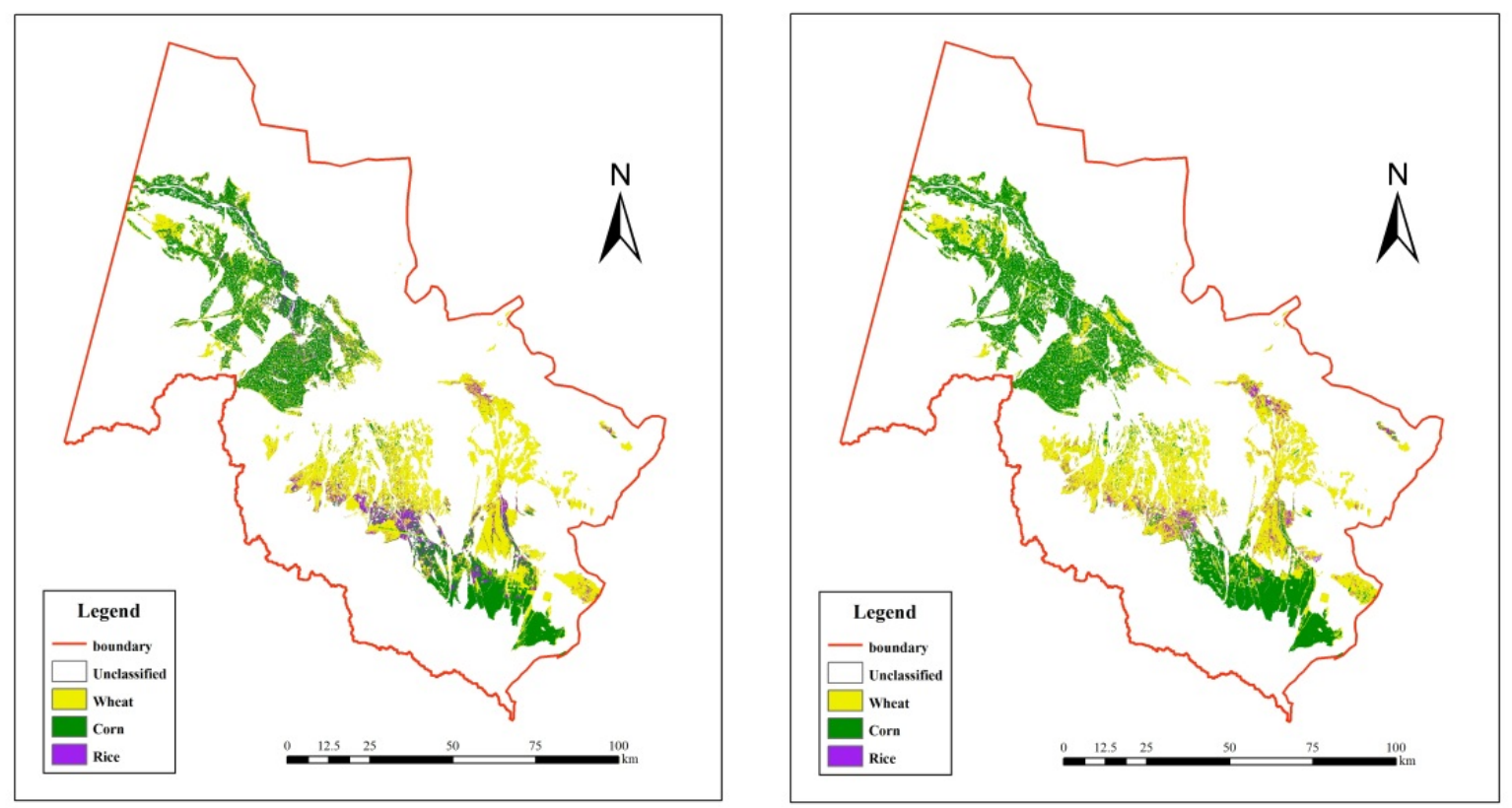

Table 6. Contingency table of 2000 LULC of agricultural land from a single Landsat scene (Path 133 Row 33).

\begin{tabular}{lccccc}
\hline Crop & Wheat & Corn & Rice & Total & User's Accuracy \\
\hline Wheat & $\mathbf{9 7 . 1 7}$ & 10.71 & 18.64 & 35.47 & 78.32 \\
Corn & 1.08 & $\mathbf{8 5 . 1 9}$ & 0.06 & 60.67 & 99.49 \\
Rice & 1.57 & 3.17 & $\mathbf{8 1 . 3 0}$ & 3.15 & 14.50 \\
Total & 100.00 & 100.00 & 100.00 & $\mathbf{1 0 0 . 0 0}$ & \\
Producer's Accuracy & 97.17 & 85.19 & 81.30 & & \\
\hline
\end{tabular}


Table 7. Contingency table of 2009 LULC of agricultural land from a single Landsat scene (Path 133 Row 33).

\begin{tabular}{llllll}
\hline Crop & Wheat & Corn & Rice & Total & User's Accuracy \\
\hline Wheat & $\mathbf{9 2 . 4 4}$ & 10.91 & 25.52 & 39.84 & 82.21 \\
Corn & 2.75 & $\mathbf{8 8 . 6 1}$ & 0.00 & 57.92 & 98.32 \\
Rice & 4.61 & 0.41 & $\mathbf{7 4 . 4 8}$ & 2.12 & 10.66 \\
Total & 100.00 & 100.00 & 100.00 & $\mathbf{1 0 0 . 0 0}$ & \\
Producer's Accuracy & 92.44 & 88.61 & 74.48 & & \\
\multicolumn{7}{l}{ Overall Accuracy $=89.92 \% ;$ Kappa Coefficient $=0.79}$. \\
\hline
\end{tabular}

\section{Discussion}

Comparing the two classification maps as showed in Figure 2, LULC change is significant: the barren land largely decreased (decreased by $1,893 \mathrm{~km}^{2}$ ), especially in the middle part of the study area. Simultaneously, the areas of agricultural land, range land and forest had expanded by about $745 \mathrm{~km}^{2}, 850 \mathrm{~km}^{2}$ and $636 \mathrm{~km}^{2}$ respectively (Figure 4). The increase of agricultural land mainly happened in the region previously to be barren land (Figure 2). More specifically, between 2000 and 2009 within the selected subset of the study area, rice planting area had declined by about $146 \mathrm{~km}^{2}$, while wheat and corn planting area both increased (Figure 5).

This change would enable the middle reach to deliver more water to the lower reach because wheat and corn uses much less water [19]. In a similar study, Qi and Luo [12] estimated the LULC changes in the HRB from 1987 to 2002 using Landsat data, and reported that cropland and urban area increased by 174.9 , and $64.6 \mathrm{~km}^{2}$, and grassland decreased by $210.3 \mathrm{~km}^{2}$ respectively, in the middle reach of the HRB during the period. Gu et al. [23] used time-series NDVI data and geographical ancillary data to classify the LULC in the HRB and, with an overall classification accuracy of $72 \%$ and the Kappa index of 0.68. Our findings are similar to those by Qi and Luo [12] and Gu et al. [23]. While lack of high resolution data and field investigations contributed to classification inaccuracies, nevertheless, the changes at least partially reflect the changing crop pattern in the middle reach of the HRB.

Figure 4. Changes in LULC classes from 2000 to 2009.

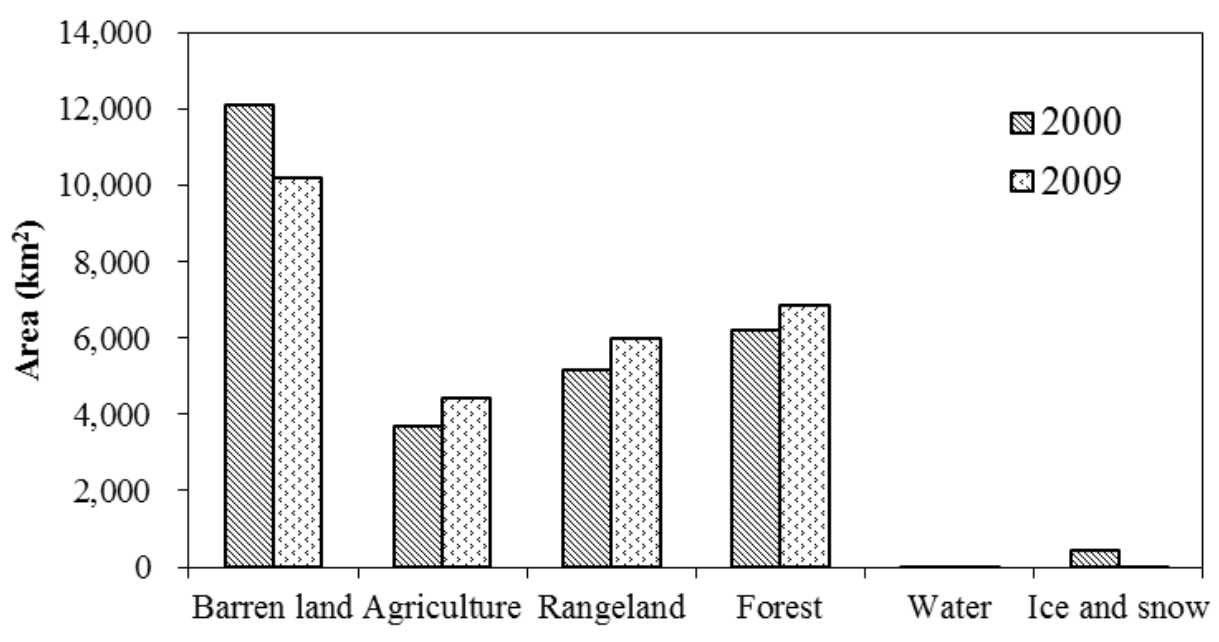


Figure 5. Changes of wheat, corn, and rice planting areas between 2000 and 2009.

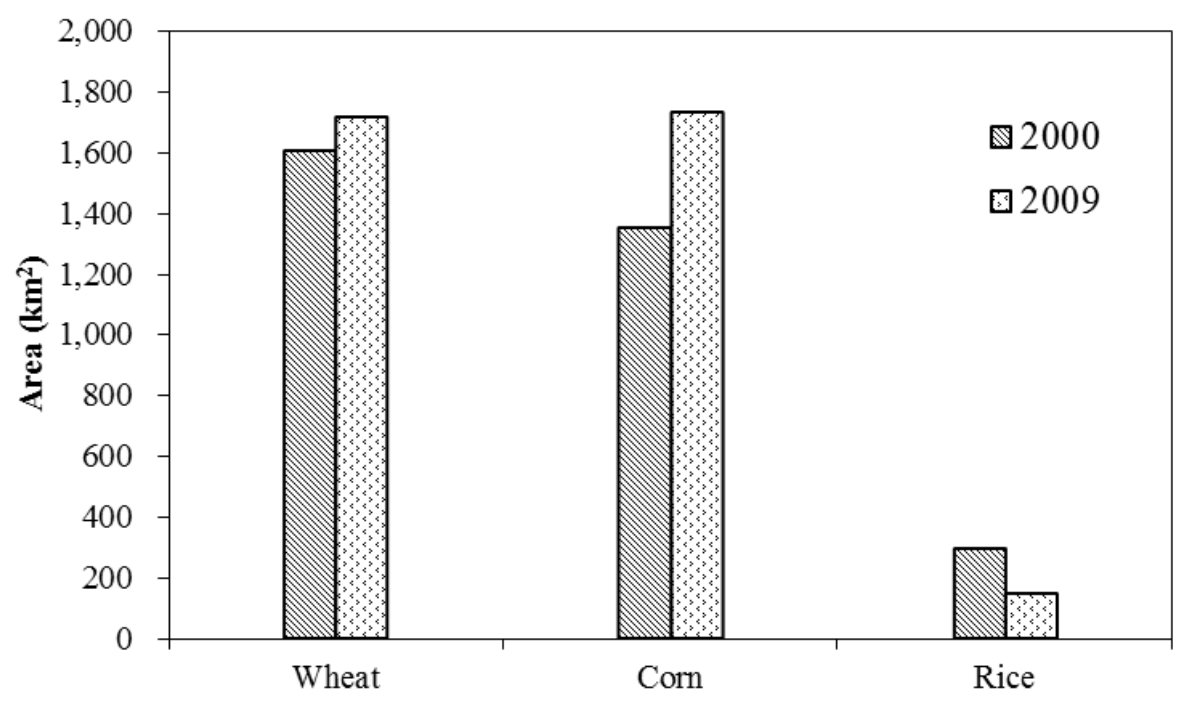

The impacts of adjusted crop patterns on water allocation can be assessed from the percentage of water allocated to the lower reach calculated from the streamflow data. The Yingluoxia and Zhengyixia gauge stations are located at the outlet of the upper and middle reach of the HRB, respectively. The water of Heihe River goes through the Yingluoxia gauge station to the middle reach and passes the Zhengyixia gauge station to the lower reach (Figure 1). Figure 6 displays the discharges of the two gauge stations from 2000 to 2009 and also the percentage of water distributed to the lower reach through the Zhengyixia gauge station over the incoming water from the Yingluoxia gauge station. After 2000, the streamflow at the Zhengyixia gauge station increased except 2004, when the flow from the Yingluoxia gauge station also declined significantly. The relationship between the precipitation of the Qilian station from 2000 to 2009 (Figure 7) and streamflow through the Yingluoxia gauge station is also evaluated.

Figure 6. Discharge of the Heihe River at the Yingluoxia and Zhengyixia gauge stations and Percentage of the total flow distributed to the lower reach of the Heihe River Basin.

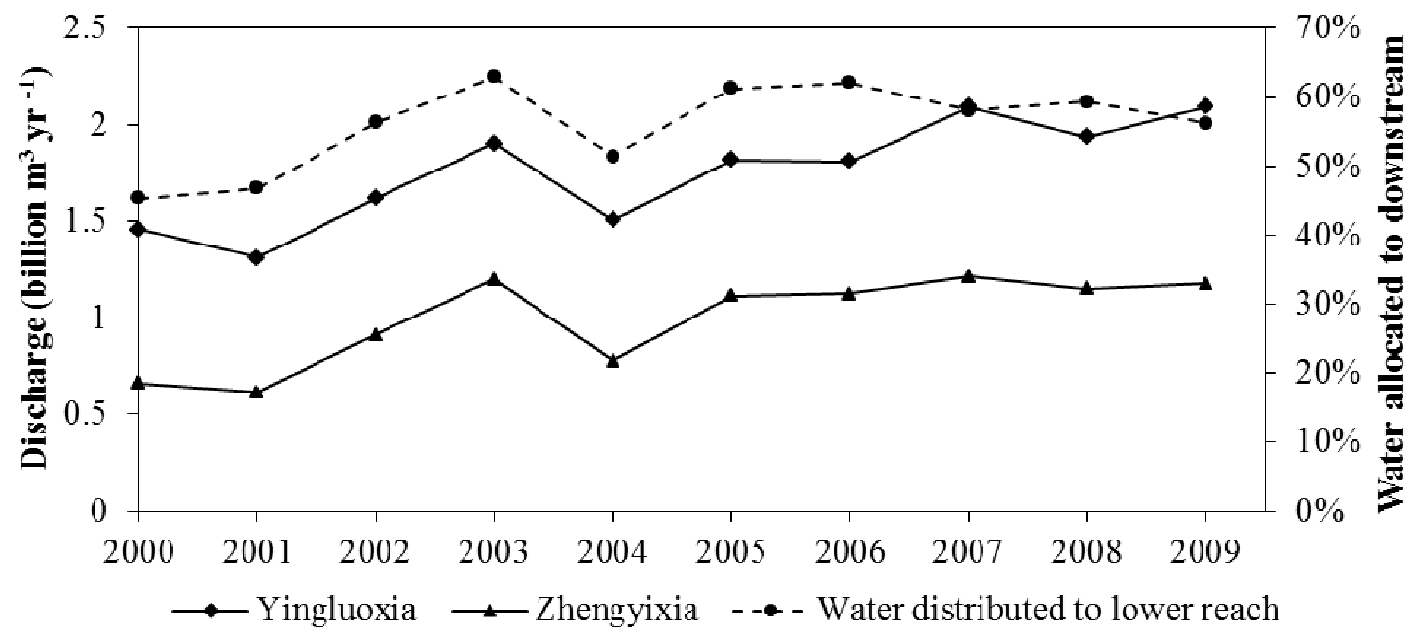


Figure 7. Annual precipitation of the Qilian station from 2000 to 2009.

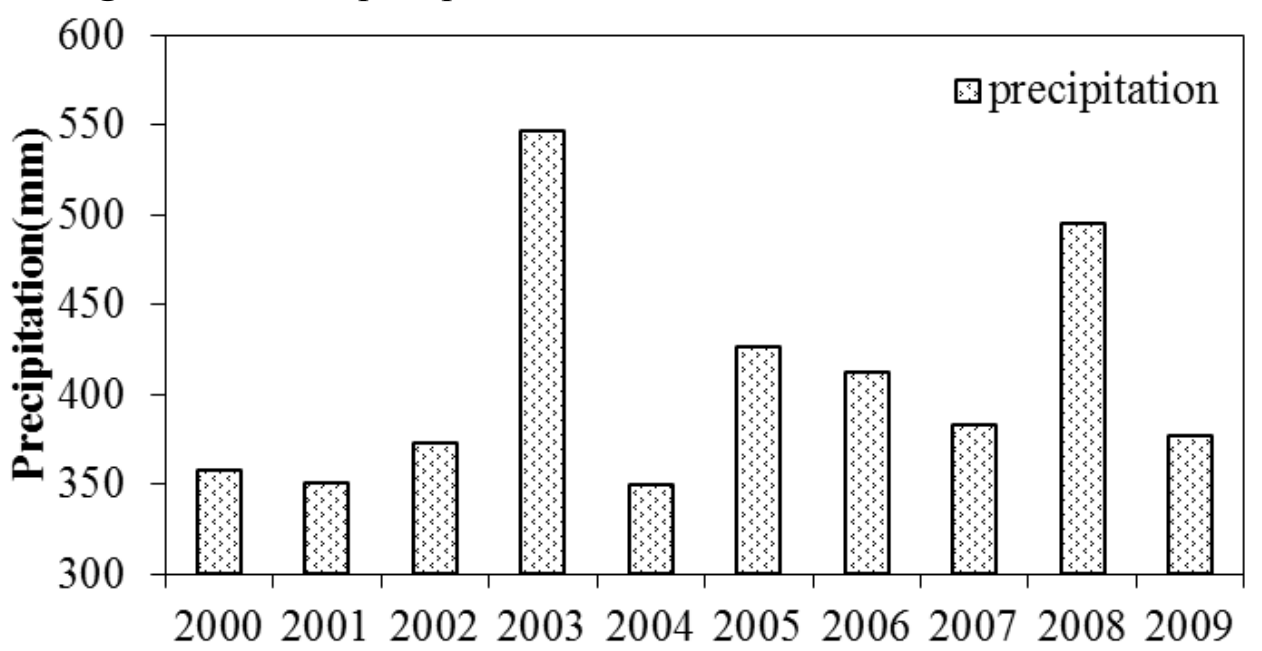

There is significant correlation $(r=0.767, p=0.016)$ between the annual precipitation and the streamflow, large amount of annual precipitation leads to higher streamflow, but the increased percentage of the discharge at the Zhengyixia gauge station to the incoming flow at the Yingluoxia gauge station stays at a relative higher rate when the precipitation seems decreasing since 2005 . This appears to indicate that the changing agricultural crop patterns have largely affected the water allocation leading to the delivery of the required discharge to the lower reach. Our findings are similar to those of $\mathrm{Wu}$ et al. [24] and Wang et al. [25]. Wu and his colleagues [24] analyzed the long-term trend of the hydrometeorological variables including air temperature and precipitation (for the period of 1959-2009) and discharges (for the period of 1978-2007) in the Upper Reach of the HRB using the nonparametric Mann-Kendall trend test. They report that the air temperature had increased significantly $(\alpha=0.05)$ for the study period [24]. However, both the precipitation and discharges didn't display a statistically significant increase for the same period [24]. Wang and his colleagues [25] who report that land use changes in the middle reach of the HRB significantly impacted the spring and winter runoff and base flow of Heihe River, and adjusting the land use structure would lead to increasing discharge to the lower reach by approximately $9 \%$, helping the restoration and reconstruction of the ecosystem in the downstream area.

\section{Conclusions}

This study conducted a comparative analysis of the changes in LULC for the period from 2000 to 2009 within the middle reach of the HRB, Northwest China using Landsat 5/Landsat 7 satellite data. The results show that, from 2000 to 2009, agricultural land, forest area, rangeland, and water area were increased, while barren land area was decreased. Within the cropland, the rice planting area had decreased, while wheat and corn planting areas had increased. These changes reduced the water consumption in the middle reach of the river and ensured the discharge of the mandated flow to the lower reach, rehabilitating the East Juyan Lake and West Juyan Lake ecosystems downstream.

This study uses a qualitative approach to assess changing crop patterns and associated impacts on water resources, which is simple, fast, and particularly useful in areas such as the HRB where land use/cover data with adequate spatial and temporal resolution are lacking. However, results from such 
assessment need to be further verified with in situ data before being used in support of land use planning and water resources management.

\section{Acknowledgements}

Partial support for this research is provided by the National Natural Science Foundation of China (Grant No: 91125010), the National Basic Research Program of Global Change (Grant No. 2010CB951002), and the CAS/SAFEA International Partnership Program for Creative Research Teams of Ecosystem Processes and Services, the Chinese Academy of Sciences (CAS) (Grant No: GJHZ0948 and CXTD-Z2005-2), and Scherer Endowment Fund of Department of Geography, Western Michigan University.

\section{Author Contributions}

$\mathrm{Li} \mathrm{Fu}$ and Chansheng He made substantial contributions to conception and design, acquisition of data, analysis and interpretation of data. Li Fu drafted the article, Lanhui Zhang and Chansheng He participated in revising it critically for important intellectual content. All authors have given final approval of the version to be submitted.

\section{Conflicts of Interest}

The authors declare no conflict of interest.

\section{References}

1. Penner, J.E. Atmospheric Chemistry and Air Quality. In Changes in Land Use and Land Cover: A Global Perspective; Meyer, W.B., Turner, B.L., Eds.; Cambridge University Press: Cambridge, UK, 1994; pp. 175-210.

2. Houghton, R.A. The worldwide extent of land-use change. Bioscience 1994, 44, 305-313.

3. Williams, M. Forests and Tree Cover. In Changes in Land Use and Land Cover: A Global Perspective; Meyer, W.B., Turner, B.L., Eds; Cambridge University Press: Cambridge, UK, 1994; pp. 97-124.

4. Robin, S.R.; Russell, L.K.; Nyawira, M.; Andualem, T.; Sara, W.; Cathleen, J.W.; Woudyalew, M. Land-use and land-cover dynamics in response to changes in climatic, biological and socio-political forces: The case of southwestern Ethiopia. Landscape Ecol. 2000, 15, 339-355.

5. Serra, P.; Pons, X.; Sauri, D. Land-cover and land-use change in a Mediterranean landscape: A spatial analysis of driving forces integrating biophysical and human factors. Appl. Geogr. 2008, 28, 189-209.

6. Lv, T.; Liu, C. Study on extraction of crop information using time-series MODIS data in the Chao Phraya Basin of Thailand. Adv. Space Res. 2010, 45, 775-784.

7. Cheema, M.; Bastiaanssen, W. Land use and land cover classification in the irrigated Indus Basin using growth phenology information from satellite data to support water management analysis. Agr. Water Manage. 2010, 97, 1541-1552. 
8. Schilling, K.; Jha, M.; Zhang, Y. Impact of land use and land cover change on the water balance of a large agricultural watershed: Historical effects and future directions. Water Resour. Res. 2008, 44, doi:10.1029/2007WR006644.

9. Schilling, K.; Chan, K.; Liu, H.; Zhang, Y. Quantifying the effect of land use land cover change on increasing discharge in the Upper Mississippi River. J. Hydrol. 2010, 387, 343-345.

10. Shupe, S. Statistical and spatial analysis of land cover impact on selected Metro Vancouver, British Columbia watersheds. Environ. Manage. 2013, 51, 18-31.

11. Wu, Y.; Liu, S.; Sohl, T.; Young, C. Projecting the land cover change and its environmental impacts in the Cedar River Basin in the Midwestern United States. Environ. Res. Lett. 2013, 8, doi:10.1088/1748-9326/8/2/024025.

12. Qi, S.; Lou, F. Land-use change and its environmental impact in the Heihe River Basin, arid northwestern China. Environ. Geol. 2006, 50, 535-540.

13. Liu, J.; Liu, M.; Deng, X.; Zhuang, D.; Zhang, Z.; Luo, D. The land use and land cover change database and its relative studies in China. J. Geogr. Sci. 2002, 12, 275-282.

14. Liu, J.; Liu, M.; Zhuang, D.; Zhang, Z.; Deng, X. Study on spatial pattern of land-use change in China during 1995-2000. Sci. China Ser. D 2003, 46, 373-384.

15. Weng, Q. Land use change analysis in the Zhujiang Delta of Chia using satellite remote sensing, GIS and stochastic modelling. J. Environ. Manage. 2002, 64, 273-284.

16. Li, X.; Yeh, A. Analyzing spatial restructuring of land use patterns in a fast gorwing region using remote sensing and GIS. Landscape Urban Plan. 2004, 69, 3335-3354.

17. Xiao, J.; Shen, Y.; Ge, J.; Tateishi, R.; Tang, C.; Liang, Y.; Huang, Z. Evaluating urban expansion and land use change in Shijiazhuang China, by using GIS and remote sensing. Landscape Urban Plan. 2006, 75, 69-80.

18. Lu, L.; Li, X.; Cheng, G. Landcape evolution in the middle Heihe RiverBasin of north-west China during the last decade. J. Arid Environ. 2003, 53, 395-408.

19. Zhao, C.; Nan, Z.; Cheng, G. Methods for estimating irrigation needs of spring wheat in the middle Heihe basin, China. Agr. Water Manage. 2005, 75, 54-70.

20. He, C.; DeMarchi, C.; Croley, T.; Feng, Q.; Hunter, T. Hydrologic modeling of the Heihe watershed by DLBRM in northwest China. J. Glaciol. Geocryol. 2009, 30, 410-421.

21. USGS EarthExplorer. Available online: http://earthexplorer.usgs.gov/ (accessed on 26 February 2014).

22. Congalton, R.G.; Oderwald, R.G.; Mead, R.A. Assessing landsat classification accuracy using discrete multivariate analysis statistical techniques. Photogramm. Eng. Remote Sensing 1983, 49, 1671-1678.

23. Gu, J.; Li, X.; Huang, C. Land Cover Classification in Heihe River Basin with Time Series-MODIS NDVI Data. In Proceedings of the Fifth International Conference on Fuzzy Systems and Knowledge Discovery, Jinan, Shandong, China, 18-20 October 2008; pp. 477-481.

24. Wu, W.; Tian, J.; Zhao, C.; Li, J.; Gu, J.; He, C. Multi-scale analysis of the long-term trend of the hydrometeorological variables in the upper reach of the Heihe River watershed, northwest China (in Chinese). Mar. Geol. Quaternary Geol. 2013, 33, 37-44. 
25. Wang, G.; Liu, J.; Kubota, J.; Chen, L. Effects of land-use changes on hydrological processes in the middle basin of the Heihe River, northwest China. Hydrol. Process. 2007, 21, 1370-1382.

(C) 2014 by the authors; licensee MDPI, Basel, Switzerland. This article is an open access article distributed under the terms and conditions of the Creative Commons Attribution license (http://creativecommons.org/licenses/by/3.0/). 